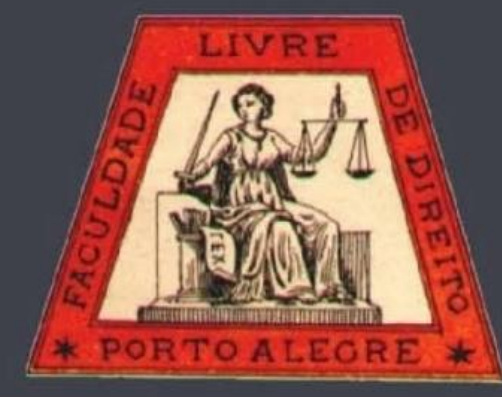

\title{
A educação inclusiva para pessoas com deficiência e o papel da UNESCO
}

Inclusive education for people with disabilities and the role of
UNESCO

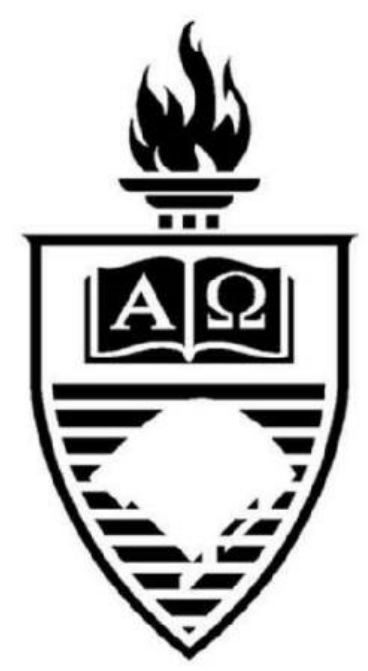

Ricardo Bispo Razaboni Junior

Centro Universitário Eurípides Soares da Rocha

Teófilo Marcelo de Arêa Leão Júnior

Centro Universitário Eurípides Soares da Rocha

Raquel Cristina Ferraroni Sanches

Centro Universitário Eurípides Soares da Rocha

\section{UFRGS}




\title{
A educação inclusiva para pessoas com deficiência e o papel da UNESCO
}

\author{
Inclusive education for people with disabilities and the role of UNESCO
}

Ricardo Bispo Razaboni Junior ${ }^{*}$

\author{
Teófilo Marcelo de Arêa Leão Júnior**
}

Raquel Cristina Ferraroni Sanches ${ }^{* * *}$

\section{REFERÊNCIA}

RAZABONI JUNIOR, Ricardo Bispo; LEÃO JÚNIOR, Teófilo Marcelo de Arêa; SANCHES, Raquel Cristina Ferraroni. A educação inclusiva para pessoas com deficiência e o papel da UNESCO. Revista da Faculdade de Direito da UFRGS, Porto Alegre, n. 38, p. 140-153, ago. 2018.

\section{RESUMO}

O presente estudo tem por objetivo abordar o instituto da educação inclusiva, a qual tem, em sentido amplo, o papel de proporcionar às pessoas de grupos "minoritários" a possibilidade de educação igualitária e digna. Porém, neste trabalho será analisada somente a educação inclusiva para as pessoas com deficiência. Abordar-se-á também o papel da UNESCO na educação inclusiva, como organização fundamental para o fortalecimento deste instituto não só no Brasil, mas em todo o mundo. Diante da problemática da educação despreparada em relação às pessoas com deficiência, conclui-se a necessidade de criar políticas para proporcionar a igualdade de oportunidades, com base, também, na dignidade da pessoa humana.

\section{PALAVRAS-CHAVE}

Educação Inclusiva. Pessoa com Deficiência. UNESCO. Dignidade da Pessoa Humana. Princípio da Igualdade.

\begin{abstract}
The purpose of this study is to address the Institute for Inclusive Education, which broadly has the role of providing people of "minority" groups with the possibility of egalitarian and dignified education. However, this paper will analyze only inclusive education for people with disabilities. The role of UNESCO in inclusive education will also be addressed as a fundamental organization for the strengthening of this institute not only in Brazil but throughout the world. Faced with the problem of unprepared education in relation to people with disabilities, it is necessary to create policies to provide equal opportunities, based also on the dignity of the human person.
\end{abstract}

\section{KEYWORDS}

Inclusive education. Disabled Person. UNESCO. Dignity of human person. Principle of Equality.

\footnotetext{
* Mestrando em Teoria do Direito e do Estado pelo Centro Universitário Eurípides Soares da Rocha, Marília, São Paulo. Graduado em Direito pela Fundação Educacional do Município de Assis (FEMA), São Paulo. Membro do Grupos de Pesquisas CNPq REI (Relações Institucionais) Todos os lados do art. $2^{o}$ da Constituição Federal e DiFuSo (Direitos Fundamentais Sociais). Realiza Estágio-Docência no curso de Graduação em Direito do Centro Universitário Eurípides Soares da Rocha, Marília, São Paulo, na disciplina Direito Civil I, ministrada pelo Prof. Dr. Teófilo Marcelo de Arêa Leão Júnior. Advogado e Consultor Jurídico.

${ }^{* * *}$ Pós-doutor em Direito pelo Ius Gentium Conimbrigae da Faculdade de Direito da Universidade de Coimbra, Portugal. Doutor em Direito pela Instituição Toledo de Ensino (ITE), Bauru, São Paulo. Mestre em Direito das Relações Sociais pela Pontifícia Universidade Católica de São Paulo (PUC-SP). Graduado pela Faculdade de Direito de Marília, hoje Curso de Direito do Centro Universitário Eurípides de Marília UNIVEM) mantida pela Fundação Eurípides Soares da Rocha, São Paulo. Líder do Grupo de Pesquisa CNPq DiFuSo (Direitos Fundamentais Sociais). Professor da Graduação e do Mestrado em Direito no Centro Universitário Eurípides Soares da Rocha, Marília, São Paulo. Advogado.

** Pós Doutora em Democracia e Direitos Humanos pela Faculdade de Direito da Universidade de Coimbra (2016), Portugal. Doutora em Educação pela Universidade Estadual Paulista Júlio de Mesquita Filho (2007), São Paulo. Mestre em Educação pela Universidade Estadual Paulista Júlio de Mesquita Filho (1998), São Paulo. Graduada em Pedagogia pela Universidade Estadual Paulista Júlio de Mesquita Filho (1992), São Paulo. Pró-Reitora de Graduação, Coordenadora da Seção de Avaliação Institucional e Docente do Programa de Mestrado em Direito do Centro Universitário Eurípides Soares da Rocha (UNIVEM), Marília, São Paulo.
} 


\section{SUMÁRIO}

Introdução. 1. A educação antecedente à constituição federal de 1988. 2. A educação e a educação inclusiva na Constituição Federal de 1988. 3. O Estatuto da Pessoa com Deficiência (Lei ñ $13.146 / 2015$ ) e a busca pela educação inclusiva. 4. O papel da UNESCO na educação inclusiva. 5. A atribuição da dignidade da pessoa humana para a educação inclusiva. 6. O papel da igualdade para a educação inclusiva. Conclusão. Referências.

\section{INTRODUÇÃO}

O presente trabalho, de cunho hipotéticodedutivo, buscará analisar o papel da educação inclusiva em relação à pessoa com deficiência. No mesmo sentido, objetivar-se-á a analise do papel da UNESCO nos ideais da educação inclusiva.

A educação inclusiva tem por objetivo recolocar no sistema de ensino pessoas excluídas, como pessoas com deficiência, distúrbios e pessoas excluídas por gênero, raça, cor ou outros motivos.

Deste modo, o objetivo principal do trabalho é analisar a educação inclusiva da pessoa com deficiência no Brasil. Porém, de modo específico, analisar-se-á o progresso desta educação, por meio de textos normativos, bem como a importância de princípios fundamentais que buscam garantir a referida inclusão educacional.

Assim, em síntese, a pesquisa trata, inicialmente, da educação em plano geral antecedente a Constituição Federal de 1988, a fim de situar os avanços da Magna Carta vigente que levaram à criação de dispositivos garantidores do ideal de educação inclusiva para pessoas com deficiência.

Abordar-se-á, também, o papel do Estatuto da Pessoa com Deficiência, que entrou em vigência no ano de 2015 e procurou estabelecer normas a fim de proporcionar e garantir a educação inclusiva das pessoas com deficiência.

O passo seguinte será estudar o papel da UNESCO para a educação, em especial, para a educação inclusiva, objetivando demonstrar a importância da instituição para a educação da aldeia global e para a inclusão educacional da pessoa com deficiência.

Diante dos fundamentos da dignidade da pessoa humana e do princípio da igualdade, os quais a UNESCO adotam como fundamentos bases da educação inclusiva, analisar-se-á o significado destes de modo puro, bem como o significado que estes têm acerca da educação inclusiva, como pilares desta educação.

Justifica-se, por fim, que o presente estudo não tem como intuito esgotar o tema, mas sim trazer informações que instiguem o debate, que se mostra essencial diante da urgência de resolução desta problemática, a fim de colaborar, também, para futuras pesquisas dedutivas e hipotéticodedutivas acerca da temática.

\section{A EDUCAÇÃO ANTECEDENTE À CONSTITUIÇÃO FEDERAL DE 1988}

A educação, direito social atualmente estabelecido na Carta Magna, é resultado de inúmeras discussões históricas, obtendo como marco inicial a discussão originada pela promulgação da Magna Carta Inglesa de 1215. Não menos importante do que os debates históricos acerca da educação, os direitos humanos assumiram papel fundamental para a esta, pois garantiram, por meio da Declaração Universal de Direitos Humanos, a educação a todas as pessoas, de forma gratuita e em plena igualdade (PISTINIZI, 2010, p. 68).

A Declaração Universal, em seu artigo $26^{\circ}$, ensina que toda pessoa humana tem direito à educação. Não obstante, prevê que o ensino elementar é obrigatório, o ensino técnico e 
profissional deve ser generalizado, devendo ser o acesso ao ensino superior igualitário, em função do mérito de cada qual. A educação deve ser direcionada ao desenvolvimento da personalidade humana e ao fortalecimento do respeito pelos direitos humanos e liberdades fundamentais. A promoção à compreensão, a tolerância e a amizade deverá ser promovida por meio da educação, entre as nações, raças e grupos religiosos.

Adentrando ao histórico nacional, tem-se que com o término do regime militar em 1985, objetivou-se reedificar a democracia brasileira. Neste período, iniciou-se um forte e constante movimento social pela promulgação de uma nova Lei Maior.

Diante do vívido apelo, instalou-se, por meio de emenda constitucional, a Assembléia Nacional Constituinte, cognominada de "Comissão Afonso Arinos", que se pautou em ideais liberais nos campos políticos e econômicos, porém não se esquecendo dos resquícios como do "patronato" e do "clericalismo", limitando-se apenas no "credencialismo", onde havia a necessidade de diploma escolar para o competente credenciamento a fim de exercitar as mais diferentes formas de trabalho. Entretanto, aos poucos, fora perdendo espaço para o princípio da igualdade e da não exigência de diploma para práticas laborais reconhecidas (PISTINIZI, 2010, p. 67).

A referida assembleia abordou temas sobre a educação, almejando incentivar a criação de mandamentos voltados à instalação de um sistema de educação de qualidade, associado ao princípio da dignidade humana.

Com a promulgação da Constituição Federal de 1988, originou-se a vigência de diversos dispositivos que tratam sobre a educação. Abordar-se-á a seguir.

\section{A EDUCAÇÃO E A EDUCAÇÃo INCLUSIVA NA CONSTITUIÇÃO FEDERAL DE 1988}

A educação é um dos mais importantes direitos sociais estabelecidos na Constituição Federal, uma vez que permite a fruição dos demais direitos. Com alicerce ao direito social da educação, o indivíduo pode ser preparado para exercer a cidadania, ser qualificado para adentrar ao mercado de trabalho, aprender a proteger sua saúde e atuar em prol do meio ambiente, ou seja, a partir da educação, poder-se-á dizer que qualquer sujeito pode ser capacitado a exercer na inteireza suas liberdades constitucionais. (MASSON, 2016 p. 1348).

Além do direito social à educação, a Constituição da República, promulgada em 05 de outubro de 1988, trouxe, em seu Capítulo III, em parte destinada à ordem social, Título VIII, os mandamentos essenciais que devem ser seguidos pelo sistema educacional brasileiro. Compreendido nos dispositivos de 205 a 214, o referido capítulo traz, de início, em seu primeiro artigo, a afirmativa de que a educação é direito de todos e dever do Estado e da família, a qual deve ser promovida e incentivada com o auxílio da sociedade, objetivando o desenvolvimento da pessoa humana, seu preparo para o exercício da cidadania e sua qualificação para o labor.

Em conseguinte, no artigo 206, o legislador constitucional previu princípios norteadores do ensino, dentre os quais valem, para este trabalho, ressaltar : I - igualdade de condições para o acesso e permanência na escola; II - liberdade de aprender, ensinar, pesquisar e divulgar o pensamento, a arte e o saber; III - pluralismo de ideias e de concepções pedagógicas, e coexistência de instituições públicas e privadas de ensino; IV - gratuidade de ensino público em estabelecimentos oficiais; VI- gestão democrática do ensino público na forma da lei; VII- garantia de padrão de qualidade. 
Adentrando ao núcleo do trabalho, ou seja, na educação inclusiva da pessoa com deficiência, verifica-se que o legislador originário concebeu, com o intuito de garantir a eficácia do princípio da igualdade de condições para o acesso e permanência na escola, o artigo 208, III, que se dedica em estabelecer o dever do Estado com a educação, o qual deve ser efetivado mediante a garantia do atendimento educacional especializado aos portadores de deficiência, preferencialmente na rede regular de ensino.

De forma não diferente trabalha o artigo $3^{\circ}$ da CF/1988 que, ao listar os objetivos fundamentais da República Federativa do Brasil, procurou garantir a construção de uma sociedade livre, justa e solidária, promovendo, também, o bem de todos, sem preconceitos de origem, raça, sexo, cor, idade e quaisquer formas de discriminação.

Ao tratar sobre a pessoa com deficiência, Eugênia Augusta Gonzaga Fávero leciona que:

[...] Isto fica bem claro quando nossa Lei Maior, além de garantir o direito à igualdade, a nãodiscriminação, elege como objetivos fundamentais da República Federativa do Brasil (art. $3^{\circ}$ ): a construção de uma sociedade livre, justa e solidária; garantir o desenvolvimento nacional; reduzir as desigualdades sociais; promover o bem de todos, sem preconceitos.

Apenas com a leitura desses objetivos já fica nítido que nossa Constituição não prevê um mero 'abrir de portas e adapte-se quem puder'. Ela impõe à República o dever de promover, de realizar ações garantidoras da não-exclusão.

Assim, quando os movimentos sociais lutam pela inclusão, não estão fazendo nada mais do que reivindicar a aplicação do princípio da igualdade, na forma como é constitucionalmente garantida no Brasil. (2004, p. 38-39).

Concluí-se, portanto, que, no âmbito jurídico, o direito à educação inclusiva compreende um direito fundamental (SANTOS; DUQUE, 2016, p. 102). Caber-se-á, assim, dizer que todos os dispositivos alusivos acima constroem a importância de estabelecer uma educação igualitária às pessoas com deficiência, sem qualquer forma de discriminação, a fim de que estas sejam incluídas na sociedade para exercer suas liberdades de forma digna.

\section{O ESTATUTO DA PESSOA COM DEFICIÊNCIA (LEI No 13.146/2015) E A BUSCA PELA EDUCAÇÃO INCLUSIVA}

A Lei Brasileira de Inclusão da Pessoa com Deficiência, cognominada como Estatuto da Pessoa com Deficiência, destina-se a assegurar e promover, em condições de igualdade, o exercício dos direitos e das liberdades fundamentais da pessoa com deficiência, visando à sua inclusão social e a cidadania.

Considerar-se-á pessoa com deficiência, conforme disposto na Lei, aquela pessoa que tem impedimento de longo prazo de natureza física, mental, intelectual ou sensorial, a qual, em interação com uma ou mais barreiras, poderá ter obstruída sua participação plena e efetiva na sociedade em igualdade de condições com as demais pessoas.

Para eventual avaliação de deficiência, o texto normativo prevê que esta será efetuada por meio da avaliação biopsicossocial, devendo ser realizada por equipe multiprofissional e interdisciplinar. Deste modo, considerar-se-á, para fins da avaliação, os impedimentos nas funções e nas estruturas do corpo; os fatores socioambientais, psicológicos e pessoais; a limitação no desempenho de atividades; e a restrição de participação.

Demonstradas as intenções principais da Lei, far-se-á a análise dos dispositivos que versam sobre a educação, obtendo como objetivo principal a educação inclusiva.

No artigo $8^{\circ}$ do Estatuto, em redação semelhante à prevista no artigo $205 \mathrm{da} \mathrm{CF}$, porém tratado de forma exclusiva a pessoa com deficiência, tem-se que é dever do Estado, da sociedade e da família assegurar à pessoa com deficiência, dentre outros direitos, a educação. 
Posteriormente, o legislador contemporâneo dedicou o capítulo IV ao direito à educação da pessoa com deficiência. Assim sendo, no artigo 27 da alusiva Lei, retira-se o mandado de que a educação constitui direito da pessoa com deficiência, devendo ser assegurado pelo sistema educacional inclusivo em todos os níveis e aprendizado ao longo de toda a vida, de forma a alcançar o máximo desenvolvimento possível de seus talentos e habilidades físicas, sensoriais, intelectuais e sociais, segundo suas características, interesses e necessidades de aprendizagem.

Perante a égide do parágrafo único do mesmo artigo, tem-se que é dever do Estado, da família, da comunidade escolar e da sociedade assegurar educação de qualidade à pessoa com deficiência, colocando-a a salvo de toda forma de violência, negligência e discriminação.

No artigo 28 do referido Estatuto, observase que é dever do poder público a criação, desenvolvimento, implementação, o incentivo, o acompanhamento e a avaliação, "in verbis", da oferta de educação bilíngue, em Libras como primeira língua e na modalidade escrita da língua portuguesa como segunda língua, em escolas e classes bilíngues e em escolas inclusivas; do acesso à educação superior, profissional e tecnológica em igualdade de oportunidades e condições com as demais pessoas; inclusão em conteúdos curriculares, em cursos de nível superior e de educação profissional técnica e tecnológica, de temas relacionados à pessoa com deficiência nos respectivos campos e conhecimento e, por fim mas não de menos importância, o poder público deve garantir a acessibilidade para todos os estudantes, trabalhadores da educação e demais integrantes da comunidade escolar às edificações, aos ambientes $\mathrm{e}$ às atividades concernentes a todas as modalidades, etapas e níveis de ensino.
Ademais, retira-se, conforme a redação do artigo 30 da Lei, que, tanto nos processos seletivos para ingresso, quanto para a permanência de pessoas com deficiência nos cursos oferecidos por instituições de ensino, sendo eles de ensino superior ou de educação profissional e tecnológicas, públicas ou privadas, devem ser adotadas medidas especiais, as quais são:

I - atendimento preferencial à pessoa com deficiência nas dependências das Instituições de Ensino Superior (IES) e nos serviços;

II - disponibilização de formulário de inscrição de exames com campos específicos para que o candidato com deficiência informe os recursos de acessibilidade e de tecnologia assistiva necessários para sua participação;

III - disponibilização de provas em formatos acessíveis para atendimento às necessidades específicas do candidato com deficiência;

IV - disponibilização de recursos de acessibilidade e de tecnologia assistiva adequados, previamente solicitados e escolhidos pelo candidato com deficiência;

V - dilação de tempo, conforme demanda apresentada pelo candidato com deficiência, tanto na realização de exame para seleção quanto nas atividades acadêmicas, mediante prévia solicitação e comprovação da necessidade;

VI - adoção de critérios de avaliação das provas escritas, discursivas ou de redação que considerem a singularidade linguística da pessoa com deficiência, no domínio da modalidade escrita da língua portuguesa;

VII - tradução completa do edital e de suas retificações em Libras.

Apesar de todos os cuidados ocupados, tanto pelo legislador constituinte, quanto pelo contemporâneo, nas redações dos dispositivos sobre educação da Constituição Federal e do Estatuto da Pessoa com Deficiência, observa-se, ainda, que a necessidade de se atingir uma educação inclusiva ideal esta longe de ser alcançada. Entretanto, a UNESCO ${ }^{1}$ possui papel chave para o futuro da educação, como se observará a seguir.

1 UNESCO fora a sigla adotada pela United Nations

Education, Scientific and Cultural Organization, que em

tradução para o português significa Organização das Nações Unidas para Educação, a Ciência e a Cultura. 
4 O PAPEL DA UNESCO NA EDUCAÇÃO INCLUSIVA

Diante da urgência nos problemas enfrentados pela comunidade internacional, temse a necessidade de efetuar ações corretivas, de grande envergadura, a fim de alcançar a solução destes. As desigualdades, a pobreza, o desemprego, a exclusão social, dentre outros problemas sociais, aterrorizou a comunidade internacional. Neste sentido, observa-se que a educação constitui, inegavelmente, uma das respostas para tais problemas. É necessário suscitar, para isso, a tomada de consciência do conjunto de problemas a serem resolvidos e procurar consensos sobre as questões que exigem uma ação combinada. Entretanto, conforme já demonstrado, a resolução destes problemas constitui tarefa de todos (DELORS, 2012, p. 157)

Porém, conforme exposto no último capítulo, a UNESCO é detentora de um papel chave para a educação. Neste trabalho, abordarse-á, como dito na parte introdutória, apenas o papel da UNESCO para com a educação inclusiva, entretanto se deve ressaltar que esta promove atos no setor da educação em geral. Assim, para a análise do papel da UNESCO na educação inclusiva, tem-se a necessidade de pontuar informações acerca desta Organização.

Fundada em 4 de novembro de 1946, a UNESCO tem como principal objetivo construir a paz e a segurança no mundo por meio da educação, ciência, cultura e comunicações.

No que se refere às suas missões e prioridades, a alusiva organização projeta contribuir para a construção da paz, reduzindo a pobreza, promovendo o desenvolvimento sustentável e o diálogo intercultural. Como objetivo máster, a UNESCO trabalha para a diminuição taxa de analfabetismo e a igualdade de gênero.
Entre as prioridades acima expostas, incluise a almejada qualidade de educação para todos, de forma continuada, buscando desafios éticos e sociais, promovendo a diversidade cultural, construindo, assim, sociedades de conhecimento inclusivo por meio da informação e comunicação.

Prosseguindo, em 1967 fora promulgado o decreto legislativo $\mathrm{n}^{\mathbf{0}}$ 40, qual aprovou a Convenção Relativa à Luta Contra a Discriminação no Campo do Ensino, adotado pela Conferência Geral da UNESCO, em Paris, na data de 14 de dezembro de 1960.

A Convenção estabeleceu que o termo "discriminação" abarca qualquer distinção, exclusão, limitação ou preferência que, por motivo de raça, cor, sexo, língua, religião, opinião pública ou qualquer outra opinião, origem nacional ou social condição econômica ou nascimento, tenha por objeto ou efeito destruir ou alterar a igualdade de tratamento em matéria de ensino.

Além disso, fora consagrado o princípio da dignidade da pessoa humana como fundamento de toda atividade educacional. Tal fato se pode verificar no trecho, retirado do próprio texto, que, ao tratar da discriminação, prevê a vedação de impor "a qualquer pessoa ou grupo de pessoa condições incompatíveis com a dignidade do homem" (SANTOS, 2012, p. 132).

A UNESCO pretende apoiar o país na implementação de ações afirmativas para promover oportunidades iguais de acesso à educação de qualidade, incluindo todos os grupos da sociedade brasileira (UNESCO).

Tais ações afirmativas, que correspondem a atos ou medidas temporárias e especiais, poderão eliminar a desigualdade educativa, incluindo crianças e jovens com deficiência na escola, com os devidos valores oferecidos pelo princípio da dignidade da pessoa humana, que já fora relevado pela UNESCO como fundamento de toda a atividade educacional, bem como com os valores 
essenciais da igualdade para resolução desta problemática.

Em termos de educação inclusiva, cabe ressaltar que a UNESCO conceitua a inclusão escolar como sendo "uma forma dinâmica de responder positivamente à diversidade dos alunos $e$ de olhar para as diferenças individuais não como problemas, mas como oportunidades para enriquecer a aprendizagem”.

Não obstante, vale lembrar que a UNESCO foi uma das agências responsáveis pela Conferência Mundial em Educação para Todos, realizada em 1994. A Conferência Mundial de Salamanca sobre Educação para Necessidades Especiais, como também é conhecida, endossou a ideia de educação inclusiva. $\mathrm{O}$ documento dela derivado, cognominado como Declaração de Salamanca, considerado como o mais significativo documento sobre educação especial, defendeu a ideia de que as escolas regulares com orientação à educação inclusiva constituem principal meio e mais eficaz para combater atitudes discriminatórias, construindo, assim, uma sociedade inclusiva com educação para todos (AINSCOW, 2009, p. 12).

Neste plano, a intenção da Educação para Todos, criada em 1990 em torno de um conjunto de políticas internacionais, coordenado principalmente pela UNESCO (AINSCOW, 2009, p. 17), é a de assegurar o acesso de educação básica de qualidade. Não obstante, implica na criação de condições que possibilitem a aprendizagem de todas as crianças, com mais ou menos capacidades. Essas condições devem, sobretudo, proporcionar um ambiente de inclusão, eficaz para as crianças, sendo simpático, acolhedor, saudável e protetor. (UNESCO, 2005, p. 7).

Deste modo, analisar-se-á os princípios constitucionais da dignidade da pessoa humana e da igualdade, sendo estes utilizados pela UNESCO e trazidos pela Conferência Mundial de Salamanca sobre Educação para Necessidades
Especiais como vetores para educação inclusiva, princípios que se revelaram de extrema importância para o crescimento desta educação e também serão essenciais para os objetivos que ainda devem ser alcançados.

\section{A ATRIBUIÇÃO DA DIGNIDADE DA PESSOA HUMANA PARA A EDUCAÇÃO INCLUSIVA}

Conforme exposto, a dignidade da pessoa humana exerce influência fundamental na construção da educação inclusiva, seja na MagnaCarta, no Estatuto da Pessoa com Deficiência, ou nas ações criadas pela UNESCO como órgão internacional detentor do papel de extrema importância na educação em geral.

Para a análise do princípio da dignidade da pessoa humana, tem-se a necessidade de se resgatar a origem desta, assim, retiram-se os ensinamentos da filosofia Kantiana:

Inúmeras foram às reflexões acerca da conceituação
da dignidade da pessoa humana. Dentre elas, as que
mais se destacaram são a ideologia cristã e a filosofia
Kantiana, as quais contribuíram para a formação do
pensamento jurídico hodierno sobre o tema. O
conceito de pessoa como um ser dotado de dignidade
teve suas origens na tradição judaico-cristã, para a
qual, segundo o texto bíblico, o ser humano foi
criado à imagem e semelhança de Deus, e desse
modo, é dotado de um valor que lhe é inerente, não
deriva da origem divina do homem. Sarlet,
entretanto, ressalta que durante um determinado
período essa ideologia foi renegada pelas instituições
cristãs e seus integrantes, quando a Santa Inquisição
cometeu crueldades contra pessoas que eram
consideradas pagãs. (SANTANA, 2011, p. 2/3).

Partindo da premissa que a dignidade supõe o direito à vida, não se pode deixar de ressaltar a importância do artigo $5^{\circ}$ da Constituição Federal, uma vez que é o dispositivo garantidor da inviolabilidade à vida.

Nesta premissa, observa-se que a Constituição Federal proclama, portanto, o direito à vida, cabendo ao Estado assegurá-lo em sua dupla acepção, sendo a primeira relacionada ao 
direito de continuar vivo e a segunda de se ter vida digna quanto à subsistência (MORAES, 2000, p.62).

Ao retratar a vida digna, resgata-se o sentido puro do princípio da dignidade da pessoa humana, o qual é magnificamente retratada por Ingo Sarlet como sendo:

[...] qualidade intrínseca e distintiva reconhecida em cada ser humano que o faz merecedor do mesmo respeito e consideração por parte do Estado e da comunidade, implicando, neste sentido, um complexo de direitos e deveres fundamentais que assegurem a pessoa tanto contra todo e qualquer ato de cunho degradante e desumano, como venham a lhe garantir as condições existenciais mínimas para uma vida saudável, além de propiciar e promover sua participação ativa e co-responsável nos destinos da própria existência e da vida em comunhão com os demais seres humanos (2007, p. 62).

Além disso, a dignidade deve ser subentendida por se mostrar como a mais importante valoração inerente a qualquer pessoa humana. Neste sentido, sob a égide do valor absoluto do ser humano, a lição de Erico Hack se faz imprescindível, pois:

A dignidade da pessoa humana é dos valores mais importantes que qualquer Estado deve observar. Isso implica ao Estado a adoção de políticas sociais, leis contra discriminação e contra qualquer condição degradante que alguém possa sofrer. Aqui também encontramos a imposição ao Estado de buscar e manter uma vida digna para todos (2008, p. 56).

Resgatado o sentido primário da dignidade da pessoa humana, tem-se a ideia de que este se mostra essencial para a educação inclusiva.

Com mais de um bilhão de pessoas com deficiência atualmente em todo o mundo, tem-se que essas pessoas geram impactos positivos e significativos na sociedade, sendo que suas contribuições podem ainda ser maiores se removermos as barreiras que impedem sua participação social, sendo isto mais importante do que nunca (KI-MOON, 2012).

Conforme destacado por Marília Dias (2010, p. 15):
[...] a educação inclusiva é uma política educacional relativamente recente, que vem gerando mudanças significativas nas escolas e nos sistemas educacionais, contudo é possível afirmar que a prática ainda precisa avançar no sentido de uma educação verdadeiramente para todos. Há um longo caminho a ser percorrido, que requer mudanças na concepção da educação e também na sociedade, pois a vivência da educação inclusiva implica necessariamente em uma comunidade inclusiva, em um entorno de compreensão e valorização dos direitos humanos.

Deste modo, as instituições de ensino devem ensinar, conviver e incluir. Assim, observa-se que o respeito à dignidade da pessoa humana ocupa papel majestoso nesta premissa. Entretanto, o direito à educação inclusiva de pessoas com deficiência não encontra sua base de fundamentação só na dignidade da pessoa humana, mas também no princípio da igualdade, o qual se analisará a seguir (BARBOSAFOHRMANN.LANES, 2011, p. 156).

\section{O PAPEL DA IGUALDADE PARA A EDUCAÇÃO INCLUSIVA}

O princípio da igualdade é representante de modo geral de todo o ordenamento jurídico brasileiro e constitui pedra angular do regime democrático. Assim, o legislador constituinte tratou a igualdade de forma especial e com robusta proteção, sendo diversas as manifestações sobre o tema no bojo constitucional, art. $3^{\circ}$, III e IV; art. $5^{\circ}$, caput e I; art. $7^{\circ}, \mathrm{XXX}$ e XXXI; art. 39, $\S 3^{\circ}$; entre outros (MASSON, 2016, p. 246).

Joaquim Barbosa revela que:

[...] segundo esse conceito de igualdade, que veio para dar sustentação jurídica ao Estado liberal burguês, a lei deve ser igual para todos, sem distinções de qualquer espécie. Abstrata por natureza e levada a extremos por força do postulado da neutralidade estatal (uma outra noção cara ao ideário 
liberal), o princípio da igualdade perante a lei foi tido, durante muito tempo, como a garantia da concretização da liberdade. Para os pensadores e teóricos da escola liberal, bastaria simples inclusão da igualdade no rol de direitos fundamentais para que a mesma fosse efetivamente assegurada no sistema constitucional. (2007, p. 48).

Ao tratar de igualdade de oportunidades, Noberto Bobbio ensina que por si mesmo e de forma abstratamente considerada, nada tem de particularmente novo, sendo que a igualdade de oportunidade não passa da aplicação da regra de justiça numa situação na qual existem várias pessoas em competição para a obtenção de um único objetivo, ou seja, um objetivo que só pode ser alcançado por um dos concorrentes (1997, p. 30).

Destaca que o que faz a importância do princípio da igualdade de oportunidades e que o torna inovador "é o fato de que ele se tenha grandemente difundido como consequência do predomínio de uma concepção conflitualista global da sociedade, segunda a qual toda a vida social é considerada como uma grande competição para a obtenção de bens escassos" (BOBBIO, 1997, p. 31).

Em outras palavras:

[...] o princípio da igualdade de oportunidades, quando elevado a princípio geral, tem como objetivo colocar todos os membros daquela determinada sociedade na condição de participar da competição pela vida, ou pela conquista do que é vitalmente mais significativo, a partir de posições iguais. (BOBBIO, 1997, p. 31).

Ao colocar a pessoa com deficiência em condições de educação igualitária a das outras pessoas, obtém-se o paradigma educacional fundamentado na concepção de direitos humanos, que conjuga a igualdade e diferença como valores indissociáveis (BRASIL, 2008, p. 9).

Assim, pode-se dizer que esta igualdade constitui o signo fundamental da democracia. Não admite os privilégios e distinções que um regime simplesmente liberal consagra (SILVA, 1990).
A Declaração de Salamanca observa um novo pensar em educação inclusiva, olhando para as escolas inclusivas como possibilidade de se constituir um ambiente favorável à aquisição da igualdade:

\begin{abstract}
A tendência em política social durante as duas últimas décadas tem sido a de promover integração e participação e de combater a exclusão. Inclusão e participação são essenciais à dignidade humana e ao desfrutamento e exercício dos direitos humanos. Dentro do campo da educação, isto se reflete no desenvolvimento de estratégias que procuram promover a genuína equalização de oportunidades. Experiências em vários países demonstram que a integração de crianças e jovens com necessidades educacionais especiais é melhor alcançada dentro de escolas inclusivas, que servem a todas as crianças dentro da comunidade. É dentro deste contexto que aqueles com necessidades educacionais especiais podem atingir o máximo progresso educacional e integração social. Ao mesmo tempo em que escolas inclusivas provêem um ambiente favorável à aquisição de igualdade de oportunidades e participação total, o sucesso delas requer um esforço claro, não somente por parte dos professores e dos profissionais na escola, mas também por parte dos colegas, pais, famílias e voluntários. A reforma das instituições sociais não constitui somente um tarefa técnica, ela depende, acima de tudo, de convicções, compromisso e disposição dos indivíduos que compõem a sociedade.
\end{abstract}

Por fim, resta claro que a dignidade da pessoa humana em cumulação com o princípio da igualdade se mostra como premissa base para a inclusão educativa e social de pessoas com deficiencia.

\section{CONCLUSÃO}

Conforme visto, toda pessoa tem o direito pleno de viver em sociedade e de ter a educação considerada ideal. Aqui se releva a necessidade de proteger a igualdade de oportunidades com equiparação aos demais. O Brasil tem o papel de promover políticas que eliminem ou reduzam ao máximo à desigualdade social, com atenção especial aos grupos considerados como minoria, diminuindo, assim, a exclusão social, 
discriminação, preconceito e violação a direitos fundamentais, como a dignidade e a igualdade.

A UNESCO, como já alusivo neste trabalho, também tem papel chave para alcançar a educação inclusiva entre as crianças e jovens. A igualdade tem de ser alcançada, não há mais espaço para qualquer meio discriminatório na sociedade contemporânea. Todas as crianças e adolescentes devem aprender juntas, sempre que possível, devendo garantir adequação às necessidades de cada um, com estratégias de ensino, uso de recurso e parcerias sociais e comunitárias.

O direito social à educação deve ser pleno e igual a todos, uma vez que visa garantir as pessoas condições de exercício e fruição de seus direitos fundamentais. Este direito proporciona as pessoas a alcançar a vida digna e o uso de suas garantias, como cidadãos.

Tanto a Constituição Federal, quanto o Estatuto da Pessoa com Deficiência, procuram garantir a igualdade e a dignidade para essas pessoas, porém como se sabe não é o suficiente. Apesar dos referidos textos normativos apresentarem relevante papel na sociedade e no direito, observa-se que a educação, em sentido geral, é falha, tendo muito ainda para chegar em um plano satisfatório, ou até mesmo um plano aceitável. Neste sentido, pergunta-se: Se a educação em plano geral é defeituosa, o que se pode imaginar da educação inclusiva?

Sabe-se que há muitos defensores da educação inclusiva, porém é lastimável observar que não há uma política de educação inclusiva fortalecida no país, e que com essa falta de política, crianças e adolescentes sofrem com a desigualdade, preconceitos e atos discriminatórios. Tais acontecimentos só corroboram para o afastamento dessas pessoas do ambiente escolar, além de ser determinante para o sentimento subjetivo destes, o que pode afetar a vivência social para o resto de suas vidas.

Deste modo, como já alusivo acima, há a necessidade de criar, intensificar e fortalecer políticas de desenvolvimento e proteção da pessoa com deficiência perante o instituto da educação inclusiva. O país, com a ajuda e o trabalho que a UNESCO exerce em panorama global, deve criar políticas a fim de alcançar a real inclusão dessas pessoas no sistema de ensino e conscientizar a população em geral sobre a importância da educação inclusiva como meio de possibilitar a essas pessoas com deficiência a igualdade de oportunidades, para que assim possam viver de modo pleno e com dignidade.

\section{REFERÊNCIAS}

AINSCOW, Mel. Tornar a educação inclusiva: como essa tarefa deve ser conceituada? In: FÁVERO, Osmar; et al. Tornar a educação inclusiva. Brasília: UNESCO, 2009.

BARBOSA, Joaquim B. A Recepção do Instituto da Ação Afirmativa pelo Direito Constitucional Brasileiro. Brasília: Ministério da Educação: UNESCO, 2007.

BARBOSA-FOHRMANN, Ana Paula; LANES, Rodrigo de Brito. O Direito à Educação Inclusiva das Crianças Portadoras de Deficiência. Revista Espaço Jurídico, v. 12, n. 1, jan./jun. 2011. Disponível em: Acesso em: 04 de abril de 2017.

BOBBIO, Noberto. Igualdade e Liberdade. 2. ed. Rio de Janeiro: Ediouro, 1997. 
BRASIL. Constituição (1988). Constituição da República Federativa do Brasil. Brasília: Senado, 1988. Disponível em: <http://www.planalto.gov.br/ccivil_03/Constituicao/Constituicao.htm>. Acessado em: 04 de abril de 2017.

- Ministério da Educação. Secretaria de Educação Especial. Política Nacional de Educação Especial na perspectiva da educação inclusiva. Revista Inclusão, 2008.

. Estatuto da Pessoa com Deficiência. Brasília: Senado, 2015. Disponível em: <http://www.planalto.gov.br/ccivil_03/_ato2015-2018/2015/lei/113146.htm>. Acessado em: 04 de abril de 2017.

DELORS, Jacques. Educação: um tesouro a descobrir. Tradução José Carlos Eufrázio. 7. ed. revisada. São Paulo: Cortez; Brasília, DF: UNESCO, 2012.

DIAS, Marília Costa. Atendimento educacional especializado complementar e a deficiência intelectual: considerações sobre a efetivação do direito à educação. 2010. Dissertação (Mestrado em Educação) - Faculdade de Educação, Universidade de São Paulo, São Paulo, 2010.

FÁVERO, Eugênia Augusta Gonzaga. Direitos das pessoas com deficiência: garantia da igualdade na diversidade. Rio de Janeiro: WVA, 2004.

HACK, Erico. Direito Constitucional, Conceitos, Fundamentos e Princípios Básicos. Curitiba: Ibpex, 2008.

KI-MOON, Ban. Mensagem no Dia Internacional das Pessoas com Deficiência: 2012. Secretário Geral. Organização das Nações Unidas (ONU). 3 dez. 2012. Disponível em <http://unicrio.org.br/diainternacional-das-pessoas-com-deficiencia-3-de-dezembro-de-2012/>. Acesso em: 08 de abril de 2017.

MASSON, Nathalia. Manual de direito constitucional. 4. ed. rev. amp. e atual. Salvador: JusPODIVM, 2016.

MORAES, Alexandre de. Direito Constitucional. 8. ed. São Paulo: editora Atlas S. A., 2000.

PISTINIZI, Bruno Fraga. O Direito à educação nas constituições brasileiras. Revista de Direito Educacional, São Paulo, vol. 2/2010, ed. jul-dez, p. 63-93, 2010.

SANTANA, Nathália Macêdo de. O princípio da dignidade humana e sua relação com o Direito Penal. Disponível em: <http://www.revistas.unifacs.br/index.php/redu/article/viewFile/1387/1074>. Acesso em 02 de abril de 2017.

SANTOS, Erick. A educação especial em face a Convenção da UNESCO contra a discriminação no campo da educação. Revista de Direito Educacional, São Paulo, vol.5/2012, ed. jan-jun, p. 125-139, 2012.

SANTOS, Bianca Goulart dos; DUQUE, Marcelo Schenk. Análise das ações afirmativas relativas à educação inclusiva no ensino do autista: a necessidade de monitor em sala de aula. Revista da Faculdade de Direito da UFRGS, Porto Alegre, n. 35, p. 99-115, dez. 2016. 
SARLET, Ingo Wolfgang. Dignidade da pessoa humana e direitos fundamentais na Constituição Federal de 1988. 5. ed. rev. e atual. Porto Alegre: Livraria do Advogado, 2007.

SILVA, José Afonso da. Curso de Direito Constitucional Positivo. São Paulo, Ed. RT, 6. ${ }^{\text {a ed., } 1990 .}$

UNESCO. Orientações para a Inclusão: Garantindo o acesso à Educação para Todos. 2005.

Recebido em: 23/10/2017

Aceito em: 18/06/2018 
